\title{
Enhanced piezoelectricity and stretchability in energy harvesting devices fabricated from buckled PZT ribbons (Withdrawal Notice)
}

Yi Qi, Prashant Purohit, Michael McAlpine

Yi Qi, Prashant K. Purohit, Michael C. McAlpine, "Enhanced piezoelectricity and stretchability in energy harvesting devices fabricated from buckled PZT ribbons (Withdrawal Notice)," Proc. SPIE 8031, Micro- and Nanotechnology Sensors, Systems, and Applications III, 80311R (13 May 2011); doi: 10.1117/12.882827

SPIE Event: SPIE Defense, Security, and Sensing, 2011, Orlando, Florida, United States 


\section{Enhanced piezoelectricity and stretchability in energy harvesting devices fabricated from buckled PZT ribbons (Withdrawal Notice)}

Proc. SPIE 8031, 80311R (2011); http://dx.doi.org/10.1117/12.882827

Online Publication Date: 13 May 2011

Withdrawn from Publication: 14 November 2013

Conference Date: 25 April 2011

Conference Location: Orlando, Florida

Conference Title: Micro- and Nanotechnology Sensors, Systems, and Applications III

Conference Chairs: Thomas George; M. Saif Islam; Achyut K. Dutta

Y. Qi,

Princeton Univ. (United States)

P. K. Purohit

Univ. of Pennsylvania (United States)

M. C. McAlpine

Princeton Univ. (United States)

This paper was presented at the SPIE conference indicated above but was submitted to the conference proceedings in error by M.C. McAlpine. The paper has been withdrawn from the SPIE Proceedings at the author's request. 